Relations industrielles

Industrial Relations

\title{
Le mouvement ouvrier aux Etats-Unis 1867-1967, par Daniel Guérin, FM/Petite collection, Paris, 1968, 176 pages.
}

\section{Bernard Solasse}

Volume 23, numéro 4, 1968

URI : https://id.erudit.org/iderudit/027960ar

DOI : https://doi.org/10.7202/027960ar

Aller au sommaire du numéro

Éditeur(s)

Département des relations industrielles de l'Université Laval

ISSN

0034-379X (imprimé)

1703-8138 (numérique)

Découvrir la revue

Citer ce compte rendu

Solasse, B. (1968). Compte rendu de [Le mouvement ouvrier aux États-Unis 1867-1967, par Daniel Guérin, FM/Petite collection, Paris, 1968, 176 pages.] Relations industrielles / Industrial Relations, 23(4), 699-699.

https://doi.org/10.7202/027960ar

Tous droits réservés @ C Département des relations industrielles de l'Université Laval, 1968
Ce document est protégé par la loi sur le droit d'auteur. L’utilisation des services d'Érudit (y compris la reproduction) est assujettie à sa politique d'utilisation que vous pouvez consulter en ligne.

https://apropos.erudit.org/fr/usagers/politique-dutilisation/ 


\section{RECENSIONS}

Le mouvement ouvrier aux Etats-Unis 1867-1967, par Daniel Guérin, FM/ Petite collection, Paris 1968, 176 pages.

Les options politiques et idéologiques de Daniel Guérin ne font aucun doute, elles sont clairement exposées dès l'avant-propos de ce petit ouvroge, où l'auteur se réfère ò Friedrich Engels et Isaac Deutscher. II est toujours intéressont de lire les écrits d'un européen, ò fortiori d'un intellectuel français de gouche sur la société américaine ou l'une de ses composantes; l'éloignement et les à priori idéologiques leur confèrent souvent un fumet bien porticulier.

Lo thèse de Daniel Guérin se résume fort simplement: le syndicalisme américain, Guérin dit le * Labor *, est un * géont endormi »; qu'il se réveille, il peut être - l'instrument décisif du socialisme ».

Si cet à priori, qui est également un pari, domine et oriente la démarche de l'auteur, celui-ci entend cependant respecter les faits et I'histoire, mais les perçoit à travers le prisme déformant de l'idéologie, et qui le conduit à surestimer, selon nous, les divergences existant dans la période octuelle entre les secteurs combatifs du « Labor * et les autres, c'est- $d$-dire entre certaines unions qui étaient affiliées à l'ancien $\mathrm{ClO}$ et d'autres qui l'étoient à la AFL. Ne faut-il pas, à tout prix, préserver le rôle et la mission historiques du mouvement et du syndicalisme ouvriers en tant qu'instrument de transformation de la société globale? Sinon I'homme de gauche rejoint inévitablement malgré toutes les nuances dont il fera étot la position d'Herbert Marcuse que, je cite ici Guérin * lors d'une rencontre d'intellectuels socialistes, d̀ New-York en septembre 1966... j'entendis affirmer d̀ l'encontre de l'enseignement du marxisme, que la classe ouvrière, dans les conditions du capitalisme avoncé, serait devenue anti-révolutionnaire, hostile au socialisme et qu'elle ne pourrait plus être considérée comme la force motrice du progrès

De tout ceci, nous tirerons deux conclusions: La première est une invitation non pcs à recuser les idéologies du moins dans la mesure où elles fournissent une problématique propre à faciliter la lecture des faits sociaux - prétendre ne pas en ovoir serait souscrire aux idées acquises - mais à les dépasser pour rejoindre au-delà des schémas et des jugements de valeur, qui les encombrent, le dynamisme et la densité des situations vécues.

La seconde est une invitation d̀ répondre à une interrogation fondamentale que nous serions tentés d'étendre au mouvement syndical conadien et qui se formulerait en ces termes: qu'en est-il aujourd'hui du rôle et de la volonté du mouvement syndical nordaméricain en tant qu'instrument de transformation de la société globale?

\section{Bernord SOLASSE}

\section{Conditions ouvrière et intégration sociale,} par J. Maire Rainville, Editions Ouvrières, Paris, 1967, 230 pp.

L'étude présentée vise d̀ connaitre a l'ajustement des ouvriers aux transformations sociales, économiques et culturelles de la société moderne ». Mais l'étude se limitant à des cas typiques ne donne qu'une image imparfaite des formes d'évolution en jeu.

Les principales variables ayant fait objet d'observations sont:

- La représentation au travail: L'intérêt au trovail ne se manifeste que lorsque tend à disparaitre l'état de subordination.

-La perception du statut social: Si l'inégalité de la condition ouvrière entraine l'affirmation des valeurs collectives, on voit aussi apparaître des niveaux d'aspirations individuelles au moyen de projets d'omélioration de niveau de vie.

-Lorientation des enfants: La plupart des ménages désirent la prolongation des études de leurs enfants et préfèrent pour eux une promotion en dehors de la voie personnellement suivie por eux.

- Les ressources et mode de vie: a) le confort familial en fonction des revenus indique une contradiction apparente entre logement vétuste et biens de consommation luxueux; b) acquis par le crédit qui amène les ménages à vivre au-dessus de leurs moyens, ce qui n'entrève pas la nécessité; c) d'autres privations pour préparer l'ovenir. 